\title{
First Description of Seronegative HTLV-1 Carriers in Argentina
}

\author{
Sandra Gallego, ${ }^{1 *} \dagger$ María C. Frutos, ${ }^{1} \dagger$ Sebastián Blanco, ${ }^{1}$ Gonzalo Castro, ${ }^{1}$ Marcos Balangero, ${ }^{1}$ David Elías Panigo, ${ }^{2}$ \\ Arnaldo Mangeaud, ${ }^{2}$ Carlos Remondegui, ${ }^{3}$ Anderson Santos Rocha, ${ }^{4,5}$ Gabriela Melo Franco, ${ }^{4,5}$ Marina Lobato Martins, ${ }^{5}$ \\ Edel Figueiredo Barbosa-Stancioli, ${ }^{4,5}$ and Silvia Nates ${ }^{1}$ \\ ${ }^{1}$ Instituto de Virología "Dr. J. M. Vanella," Facultad de Ciencias Médicas, Universidad Nacional de Córdoba, Córdoba, Argentina; ${ }^{2}$ Departamento \\ de Matemática, Facultad de Ciencias Exactas, Físicas y Naturales, Universidad Nacional de Córdoba, Córdoba, Argentina; ${ }^{3}$ Servicio de \\ Infectología y Enfermedades Tropicales, Hospital San Roque, San Salvador de Jujuy, Argentina; ${ }^{4}$ Laboratorio de Virología Básica e Aplicada, \\ Departamento de Microbiología, Instituto de Ciencias Biológicas, Universidad Federal de Minas Gerais-UFMG, Belo Horizonte, Brasil; \\ 5 Interdisciplinary HTLV Research Group, Belo Horizonte, Brasil
}

\begin{abstract}
In some areas of Argentina endemic for human T-lymphotropic virus type 1 (HTLV-1), tropical spastic paraparesis is frequent in subjects who lack antibodies against the virus; however, the relevance of this seronegative status in the country has not been investigated. In neighboring countries, HTLV-1 seronegative status has been described in patients with different diseases; however, data regarding features of seronegative HTLV-1 carriers are scarce. We investigated the seronegative status in 124 relatives of 28 HTLV-1 infected subjects from an endemic area in Northwest Argentina. Blood samples and clinical/epidemiological data were collected. Human T-lymphotropic virus type 1 infection was diagnosed by serology and long terminal repeat (LTR) sequence, env and tax gene detection. IgG anti-Tax HTLV-1 antibody, tax gene sequence, and DNA proviral load were also evaluated. Seventy-five percent of the 124 relatives were negative for HTLV-1/2 antibodies; $35.5 \%$ were also negative by molecular assays and $64.5 \%$ were negative for HTLV-1 LTR and env sequences, but positive for two sequences of HTLV-1 tax gene. Also, 35.7\% of these subjects had lgG antiTax antibodies. The seronegative HTLV-1 status was significantly associated with male gender, youth, and sensory symptoms/autonomic nervous system dysfunction. High rates of seronegative symptomatic and asymptomatic HTLV-1 carriers in Argentina are described. The evidence highlights that HTLV-1 prevalence may be underestimated worldwide. Larger cohort studies are required to assess disease outcome in these seronegative subjects. Also, the findings emphasize the limitations of ongoing screening assays for diagnosis and blood safety. Therefore, algorithms for HTLV-1 diagnosis should include not only serological but also molecular assays.
\end{abstract}

\section{INTRODUCTION}

Human T-lymphotropic virus 1 (HTLV-1) is a human oncoretrovirus responsible for adult T-cell leukemia/lymphoma and tropical spastic paraparesis/HTLV-1-associated myelopathy (TSP/HAM). Human T-lymphotropic virus 1 infects at least 5-10 million people worldwide through blood and sexual/vertical routes. 1

Infection and diseases associated with HTLV-1 have been reported in almost all South American countries, including Brazil, Colombia, Argentina, Peru, French Guiana, and Chile. ${ }^{2}$ Prevalence rates of infection vary within each country according to different geographic areas. Some zones of South America, such as Northeast Brazil and Northwest Argentina, are considered endemic for HTLV-1. ${ }^{1}$ In Argentina, the prevalence rate in blood donors of endemic zones is $0.6-1.2 \%$, whereas in nonendemic areas, it is $<0.1 \%{ }^{1}$ An ongoing silent transmission of HTLV-1 through vertical and sexual routes within family clusters of Northwest Argentina has been demonstrated. ${ }^{2}$

Diagnosis of HTLV-1 infection is reached mainly by detection of specific antibodies by particle agglutination assays (PAs) or chemiluminescent microparticle immunoassay (CMIA), or enzyme immunoassay (ELISA) and subsequent confirmation by Western blot or indirect immunofluorescence assays (IFAs). ${ }^{1}$

Although it is assumed that HTLV-1 causes persistent infection in which virus and specific antibodies coexist,

\footnotetext{
*Address correspondence to Sandra Gallego, Instituto de Virología "Dr. J. M. Vanella," Facultad de Ciencias Médicas, Universidad Nacional de Córdoba, Enfermera Gordillo Gómez s/n Ciudad Universitaria, Córdoba 5016, Argentina. E-mail: svgallego@gmail.com † Sandra Gallego and María Celia Frutos are CONICET scientific member.
}

sporadic publications report absence of antibodies in virus carriers. In this sense, some authors have described seronegative TSP/HAM patients infected with HTLV-1.,4

In Chile, one of the countries with highest prevalence of TSP/HAM worldwide, several TSP/HAM patients infected with HTLV-1 but with negative serology have been described. ${ }^{4,5}$ In this cohort, seropositive and seronegative patients with TSP/ HAM were clinically indistinguishable. ${ }^{4,5}$ Moreover, in seronegative patients, the presence of HTLV-1 tax sequences in peripheral blood mononuclear cells (PBMCs) and cerebrospinal fluid cells was demonstrated. ${ }^{5,6}$ Later, de Oliveira et al. ${ }^{7}$ reported this atypical profile of infection in patients with infective dermatitis (ID), showing molecular evidence of infection in two of 42 patients serologically negative for HTLV-1. Similar findings arose from patients with cutaneous T-cell lymphoma without antibodies to structural proteins of HTLV1,8 who expressed Tax mRNA and presented antibodies to p40 Tax in lymphocytes infiltrating skin and keratinocytes. Likewise, this condition was found in patients with autoimmune diseases such as rheumatoid arthritis, who had antibodies to Tax protein alone in the blood. ${ }^{9}$

The seronegative condition in HTLV-1 infection was also described in patients with mycosis fungoides (MF), who harbored the tax sequence of HTLV-1 in their lymphocytes without presenting antibodies to the structural proteins of the virus $^{10}$; this situation was also found in healthy relatives of MF patients. $^{11}$

San Salvador de Jujuy, located in Northwest Argentina, is an endemic area for HTLV-1 with a high rate of intrafamilial transmission of the virus and foci of HTLV-1-associated TSP/ HAM. ${ }^{1,2}$ Local physicians have noticed that signs/symptoms of TSP/HAM are frequent in subjects who lack antibodies against the virus. Because in Argentina HTLV-1/2 diagnosis is 
performed exclusively by serological methods and given that the named seronegative condition in HTLV-1 carriers within the country has not been studied, we investigated the seronegative profiles in the family members of HTLV-1 seropositive patients in San Salvador de Jujuy, Argentina.

\section{METHODS}

A cross-sectional study of 152 subjects from San Salvador de Jujuy, Argentina, was carried out; 28 with HTLV-1 infection confirmed by serology and 124 close relatives. The 28 infected subjects (one asymptomatic and 27 with neurological signs/ symptoms, being $16 \mathrm{HAM} / \mathrm{TSP}$ cases) were randomly selected from the records of San Roque Hospital, San Salvador de Jujuy. One hundred and fifty-five relatives of the infected subjects were invited to participate and $80 \%$ of them accepted to be enrolled in the study.

Blood samples were codified as ArJ followed by a number. The study was approved by the Ethics Committee of San Roque Hospital on April 22, 2015. Written informed consent was signed by all participants and a structured questionnaire was applied to collect clinical and epidemiological data. Clinical examination of all the relatives enrolled was carried out double blind. Once the HTLV status was determined, the professionals informed and advised the patients about HTLV-1 infection and incorporated them in the public health-care system so they can receive medical support from a multidisciplinary team.

Serological assays. All subjects were tested for HTLV-1/2 antibodies by Architect rHTLV-I/II assay (Abbott Laboratories, Weisbaden, Germany) and PA assay (Serodia Fujirebio Inc., Tokyo, Japan). All samples were further analyzed with an "inhouse" IFA on MT-2 cell line. ${ }^{12}$ The positive criterion was defined as reactive for any Architect $\mathrm{rHTLV}-\mathrm{I} / \mathrm{II}$ assay or PA assay and positive by IFA.

Polymerase chain reaction (PCR) assays. High molecular weight DNA was extracted from whole-blood samples of all subjects. Polymerase chain reaction was carried out to amplify 219-bp sequence of the tax gene following protocols previously described. ${ }^{13}$ All samples were typed by nested PCR for HTLV-1 and HTLV-2 targeting the tax region. ${ }^{13}$ Polymerase chain reaction products were separated on a $2 \%$ agarose gel and visualized under ultraviolet light (UV) after ethidium bromide staining.

Amplification of $1,119 \mathrm{bp}$ of the tax region from the viral genome was performed in all tax-positive samples. ${ }^{14}$ A 561bp segment from the env gene and 672-bp segment from the LTR region were amplified by nested-PCR. ${ }^{15}$

Proviral load quantification was performed in DNA extracted from PBMCs obtained by Ficoll-Hypaque gradient from all taxpositive samples using quantitative real-time PCR assay. ${ }^{16}$

Sequencing. Polymerase chain reaction products corresponding to HTLV-1 tax sequences were purified using QIAquick Gel Extraction Kit (Qiagen, Valencia, CA) according to the manufacturer's instructions. The tax fragments (1,119 bp) were subjected to direct nucleotide sequencing reaction in both directions using the internal PCR primers by Macrogen, Inc. (Seoul, Korea). The alignment of all tax sequences from HTLV-1 seronegative and HTLV-1 seropositive subjects was performed using Clustal W program (Conway Institute UCD Dublin, Dublin, Ireland) and compared with Pairwise/Blast/ NCBI. Sequences were deposited in GenBank (Accession number MK638973-MK638980).
Anti-Tax-IgG ELISA. The partial C-terminal HTLV-1 Tax region ${ }^{17}$ cloned in the $\mathrm{PQE}$ system and expressed in Escherichia coli M15 (rec-Tax) was used as coating protein in the ELISA assay (150 ng/well). After incubation for 16 hours at $4^{\circ} \mathrm{C}$, the plates were washed (phosphate buffer [PBS]; $0.1 \%$ Tween 20; and $0.1 \%$ bovine fetal bovine serum [FBS]) and blocked with $3 \%$ FBS diluted in PBS for 2 hours at $37^{\circ} \mathrm{C}$. Diluted sera samples (1:50) were added to plates and incubated at $4^{\circ} \mathrm{C}$ for 16 hours, followed by washing seven times. The reactions were developed using anti-IgG-HRP (1:25.000; SigmaAldrich, St. Louis, MO), incubated at room temperature for 90 minutes, followed by washing five times. The substrate ophenylenediamine dihydrochloride (OPD) was added. The reaction was stopped by addition of $1 \mathrm{M} \mathrm{H}_{2} \mathrm{SO}_{4}$ and read at $492 \mathrm{~nm}$ in spectrophotometer Multiskan Spectrum V. 1.2 (Thermo Scientific, Waltham, MA).

Sensitivity and specificity of the test were previously assessed by testing 51 Brazilian seronegative blood donors and 34 Brazilian HTLV-1 seropositive individuals (18 asymptomatic carriers and $16 \mathrm{HAM} / \mathrm{TSP}$ patients), confirmed by western blot (WB) (WB HTLV 2.4, Genelabs Diagnostics, Singapore). Sensitivity was $52.9 \%$ (95\% Cl: 35.1-70.2\%) and specificity was 100\% (Cl: 93.0-100\%). Samples from 12 seronegative Brazilian blood donors were included and used to determine the cutoff value, considered as the mean optical density (OD) of the negative controls plus $1.5 \times \mathrm{SD}$. This test was performed at the Laboratório de Virologia Básica e Aplicada da Universidade Federal de Minas Gerais, Belo Horizonte, Brazil.

Statistical analysis. Means and SDs were calculated for continuous variables. The test of proportions was used to compare categorical variables. Distribution of frequencies for each variable was evaluated by Chi-square test and quantitative variables with One-way analyses of variance (ANOVA) or Kruskal-Wallis test. RMedic was used for statistical analyses. ${ }^{18}$ Statistical analyses of IgG anti-Tax antibody were conducted using GraphPad Prism6 software (GraphPad Software Inc., San Diego, CA) Unpaired T-test and anti-Tax IgG reactivity and DNA proviral load of HTLV-1 analyses were correlated by means of Spearman correlation coefficients. Significance was assumed at $P<0.05$.

\section{RESULTS}

Thirty-one (25\%) persons of the 124 relatives of 28 seropositive subjects had antibodies against HTLV-1/2 detected by Architect, PA, and IFA. All the 59 seropositive subjects had HTLV-1 provirus in blood detected by nested-PCR for tax, env, and LTR regions.

Ninety-three (75\%) of 124 relatives were negative for HTLV1/2 antibodies by Architect, PA, and IFA. Thirty-three (35.5\%) of them were also negative for molecular assays and 60 (64.5\%) negative for HTLV-1 LTR and env sequences, but positive for two sequences of HTLV-1 tax gene using different PCRs (100 bp and 1,119 bp). These 60 subjects showed molecular evidence of infection; however, they had no antibodies against structural HTLV antigens detectable with commercially available CE-marked or FDA-approved HTLV-1/ 2 screening assays.

From the total 119 HTLV-1 carriers (91 relatives and 28 original cases), 65 (54.6\%) were women and 54 (45.4\%) men; mean age at time of study: 36.53 years (2-83 years); 30 (25\%) were asymptomatic and 89 (75\%) symptomatic. Most 
symptomatic subjects had two or more associated symptoms: $52.8 \%$ (47/89) motor symptoms and signs, $78.6 \%$ (70/89) sensory, 39.3\% (35/89) peripheral symptoms, and $41.6 \%$ (37/89) autonomic nervous system dysfunction. Motor symptoms included hyperreflexia of lower limbs $25 \%(22 / 89)$, hyperreflexia of upper limbs $12.4 \%$ (11/89), weakness of lower limbs in $37 \%$ (33/89), and positive Babinsky sign in $25 \%$ (22/89). Abolition of cutaneous-abdominal reflexes was detected in $25 \%(22 / 89)$ of the subjects and $11.2 \%$ (10/89) presented muscular atrophy.

Sensory signs and symptoms were sensory disturbance (paresthesia, pain, and burning) in $42.7 \%$ (38/89), low lumbar irradiated pain in $47.2 \%(42 / 89)$, reduced vibratory sense in $22.5 \%(20 / 89)$, tremors in $12.4 \%$ (11/89), and visual impairment in $40.4 \%$ (36/89) of the subjects.

Neurological findings as hearing loss, nystagmus, and other cranial nerve deficits were found in 18\% (16/89), 2.2\% (2/89), and $9 \%(8 / 89)$, respectively. Cerebellar signs were detected in $21 \%$ (19/89), reduced Achilles reflex in 18\% (16/89), and signs of peripheral neuropathy in $3.4 \%$ (3/89) subjects.

Autonomic nervous system dysfunction as impotence in $12.4 \%(11 / 89)$ and bladder disturbance in 39\% (35/89) subjects were also observed.

Among seropositive subjects ( 38 women and 21 men), the average age was 45 years (3-83 years) and in seronegative HTLV-1 carriers (27 women and 33 men), average age was 24 years (2-75 years). Median age was significantly higher in seropositive subjects $(P<0.01)$ (Table 1$)$. Among seronegative HTLV-1 carriers, $28.3 \%$ had any of the parents infected with HTLV-1: 11 had infected mother, two had infected father, and four had both mother and father infected.

Most infected women were seropositive and male gender was significantly associated with seronegative HTLV-1 carrier condition $(P=0.04)$ (Table 1).

Although $60 \%(36 / 60)$ of seronegative HTLV-1 carriers presented symptoms, a significant association was found between seronegative condition and absence of symptoms $(P<0.01)$ when compared with seropositive patients; $90 \%$ $(53 / 59)$ of them were symptomatic. Table 1 details the signs/ symptoms of the two groups. A significant association was observed between sensory signs/symptoms or autonomic nervous system dysfunction and seronegative condition $(P<$ 0.01 ). Nevertheless, there was a significant association between motor signs/symptoms and seropositive condition $(P<0.01)$. No significant association was observed between peripheral symptoms and serological condition $(P=0.56)$, being the variables statistically independent.
The proviral load was measured in the peripheral blood of 40 seropositive and 14 seronegative HTLV-1 carriers. Viral load of seropositive subjects ranged between $373.81-82,351.10$ copies $/ 10^{6}$ PBMCs and 147.05-7,425.09 copies $/ 10^{6}$ PBMCs in seronegative individuals. The median proviral load of seropositive subjects $\left(4,756.73\right.$ copies $/ 10^{6}$ PBMCs) was significantly higher than seronegative ones: 621.22 copies $/ 10^{6}$ PBMCs $(P<0.01)$ (Table 1).

A sequence of 1,119-bp tax gene was amplified and detected in all seronegative HTLV-1 carriers. To corroborate the identity of the amplified fragments, samples from eight seronegative subjects were randomly selected and sequenced. Sequences of $1,004 \mathrm{bp}$ were compared with those corresponding to 26 randomly selected seropositive subjects from endemic areas of Argentina (GenBank accession numbers: DQ227149; DQ227152, DQ227154, DQ227155, DQ227158, DQ227161, DQ227164, DQ227166, DQ227169, DQ227171DQ227176, DQ227178, DQ227181-DQ227183, and DQ227185DQ227191) and with the HTLV-1 prototype clone ATK-1 (GenBank accession number J02029) as reference (Figure 1). The high homology found between strains corroborated that all sequences corresponded to HTLV-1. Thus, in comparison with ATK-1, sequences from seronegative subjects ArJ03-06, ArJ13-01, ArJ24-01, ArJ26-02, ArJ26-04, and ArJ41-03 showed 99.6\% homology and sequences from ArJ25-05 and ArJ44-02 presented $99.5 \%$ and $99.3 \%$ homology, respectively (Figure 1).

Seronegative HTLV-1 carriers had three nucleotide changes at position 7920,7982 , and 8230 , compared with the sequence of ATK-1; these changes were also noticed in seropositive subjects. Five seronegative subjects (ArJ03-06, ArJ13-01, ArJ24-01, ArJ26-02, and ArJ41-03) had a common nucleotide change at position 8002 compared with ATK-1; four of them (ArJ03-06, ArJ13-01 ArJ24-01, and ArJ26-02) had also a nucleotide change at position 8295; both mutations were absent in seropositive subjects. These mutations did not produce any change on amino acids of Tax protein.

Intending to find serological evidences in seronegative subjects infected with HTLV-1, a search for IgG antibodies against HTLV-1 Tax protein (IgG anti-Tax) with an "in-house" ELISA assay was carried out in serum samples of 42 seronegative and 10 seropositive subjects. IgG anti-Tax HTLV-1 antibodies were detected in $35.7 \%(15 / 42)$ of seronegative and $80 \%(8 / 10)$ of seropositive subjects, respectively. Statistical significance $(P<0.0001)$ was found when the OD of IgG anti-Tax antibodies was compared between groups, being greater among seropositive (mean OD: 0.724; 0.220-1.425) than in seronegative subjects (mean OD: $0.338 ; 0.064-0.852$ ).

TABLE 1

Demographic and clinical features of seropositive and seronegative human T-lymphotropic virus type 1 carriers from Argentina

\begin{tabular}{|c|c|c|c|c|c|c|c|c|}
\hline \multirow[b]{2}{*}{ Serology status } & \multicolumn{2}{|c|}{ Gender } & \multirow[b]{2}{*}{ Age (years) ${ }^{*}$} & \multicolumn{4}{|c|}{ Signs and symptoms } & \multirow{2}{*}{$\begin{array}{l}\text { Proviral load (copies } / 10^{6} \text { peripheral } \\
\text { blood mononuclear cells) } \dagger\end{array}$} \\
\hline & Female & Male & & Motor & Sensory§ & Peripherall & A.N.S.D. & \\
\hline Seropositive, $N(\%)$ & $38(64.4)$ & $21(35.6)$ & 45 & $36(77) \#$ & $28(46)$ & $17(48)$ & $12(32)$ & 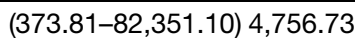 \\
\hline Seronegative tax-positive, $N(\%)$ & $27(45)$ & $33(55)$ & 24 & $11(23)$ & $42(71) \#$ & $18(52)$ & $25(68) \#$ & $(147.05-7,425.09) 621.22$ \\
\hline$P$-value ${ }^{* *}$ & \multicolumn{2}{|c|}{0.04} & $<0.01$ & $<0.01$ & $<0.01$ & 0.79 & $<0.01$ & $<0.01$ \\
\hline Seronegative, $N(\%)$ & $17(51.5)$ & $16(48.5)$ & 21 & 0 & 0 & 0 & 0 & Not applicable \\
\hline
\end{tabular}

${ }^{*}$ Median value.

† Range and median value.

$\ddagger$ Motor symptoms: hyperreflexia of lower limbs, hyperreflexia of the upper limbs, abolition of cutaneous-abdominal reflexes, muscular atrophy, weakness of lower limbs, and Babinski signs

$\S$ Sensory symptoms: paresthesia, pain, and burning; low lumbar pain, reduced vibratory sense, tremors, visual impairment, hearing loss, and nystagmus.

I Peripheral symptoms: cerebellar signs, diminished Achilles reflex, cranial nerve deficits, and peripheral neuropathy.

- Autonomic nervous system dysfunction (A.N.S.D.): impotence and bladder disturbance.

\# Significative higher frequency.

${ }^{*}$ Chi-square test. 


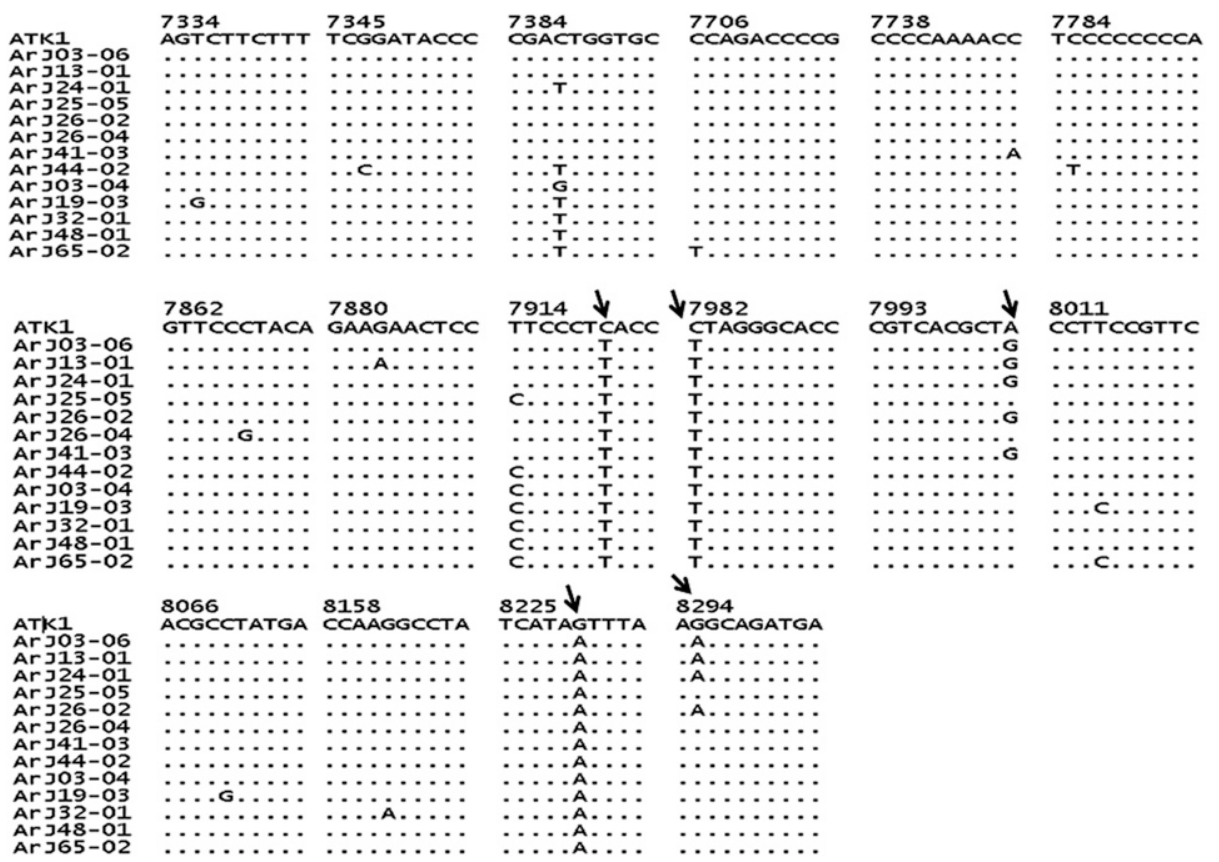

FIGURE 1. Nucleotide sequence of 1004 bp of the tax gene from Argentinean human T-lymphotropic virus type 1 (HTLV-1) seronegative ArJ03-06 (MK638973); ArJ13-01 (MK638974); ArJ24-01(MK638975); ArJ25-05(MK638976); ArJ26-02(MK638977); ArJ26-04(MK638978); ArJ41-03(MK638979); ArJ44-02(MK638980) and seropositive ArJ03-04 (DQ227152); ArJ19-03 (DQ227166); ArJ32-01 (DQ227174); ArJ48-01 (DQ227186); ArJ65-02 (DQ227191) subjects. Dots represent residues that are identical to ATK. The first and last residues in the HTLV-1 tax gene are provided as well as their position in the ATK genome. The arrow indicates nucleotide changes at the positions $7920,7982,8002,8230$, and 8295 compared with HTLV-1 prototype clone ATK-1.

The load of IgG anti-Tax antibody distribution was homogeneous among seronegative carriers (Figure 2).

No correlation between HTLV-1 DNA proviral load and antiTax IgG reactivity was noted among seronegative or seropositive groups $(P>0.05)$ (Figure 3 ).

\section{DISCUSSION}

This study describes for the first time a high rate of seronegative HTLV-1 carriers in an endemic zone of Argentina. From 93 seronegative relatives of HTLV-1 carriers, 64.5\% showed molecular evidence of infection through tax sequence detection; none presented detectable antibodies with commercially available CE-marked or FDA-approved HTLV-1/2

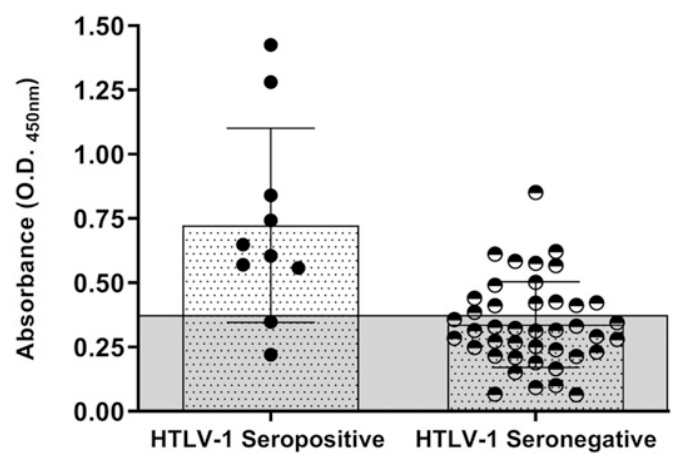

FIGURE 2. Optical density (OD) of IgG Anti-Tax human T-lymphotropic virus type 1 (HTLV-1) antibodies detected by ELISA in HTLV-1 seropositive and HTLV-1 seronegative infected subjects. The gray area represents the cutoff $(O D=0.371)$ of the assay. This figure appears in color at www.ajtmh.org. screening assays. To our knowledge, despite one article from a U.S. blood bank, ${ }^{19}$ data regarding seronegative status in HTLV-1 carriers from general population is scarce. Moreover, findings about seronegative HTLV-1 carriers have been described in groups of TSP/HAM patients from different countries, ${ }^{3,5}$ in HTLV-1 infected patients with $\mathrm{MF}^{10,11}$ and their relatives ${ }^{11}$ in addition to subjects with $\mathrm{ID}^{7}$ or hematological diseases. ${ }^{20-22}$ This is the first report of seronegative profiles in symptomatic and asymptomatic HTLV-1 infected subjects in Argentina. Our results indicate that prevalence rates of HTLV$1 / 2$ infection settled down by serology could be underestimated and corroborate the strong silent dissemination of HTLV-1 infection in Northern Argentina, as we have previously reported. ${ }^{2}$ Furthermore, we think that this phenomenon is not exclusive of endemic areas of Argentina but also of other countries. Thus, in a Chilean study, ${ }^{20}$ an underestimated HTLV-1 prevalence was demonstrated among patients with malignant hematological diseases. This study found a high rate of malignant hematological diseases $(81.3 \%, 13 / 16)$ in HTLV-1/2 infected seronegative patients, resembling previous studies of Chilean TSP/HAM patients with $40 \%$ of seronegative status. ${ }^{4,5}$ Thereby, our results, together with current evidence from other countries, highlight that HTLV-1 prevalence may be underestimated worldwide and in different population groups.

Because in this study, seronegative status among HTLV-1 infected subjects was significantly associated with male gender (Table 1) and considering that HTLV diagnosis in adults is routinely performed by serology alone, rates of viral infection mainly for men are certainly underestimated in endemic areas of Argentina. Furthermore, because seronegative infected HTLV-1 subjects were significantly younger than seropositive 

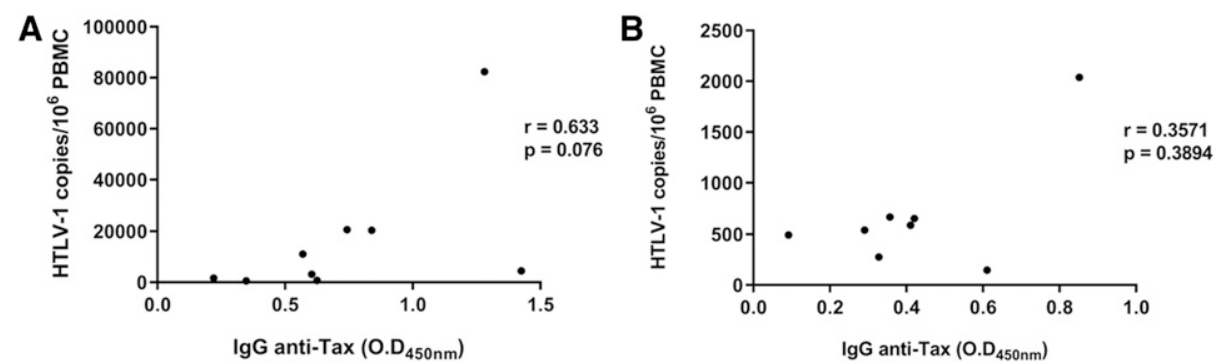

FIGURE 3. Correlation between IgG anti-Tax reactivity and human T-lymphotropic virus type 1 (HTLV-1) DNA proviral load in seropositive (A) and seronegative (B) HTLV-1 infected groups.

ones, the seronegative condition among HTLV-1 infected people would be mainly associated with male gender and youth. This finding differs from the data described for TSP/ HAM patients and subjects with malignant hematological diseases, for whom no relationship was observed between gender and seronegative status in HTLV-1 carriers. ${ }^{5,20}$

Although Northwest Argentina is a recognized endemic area for HTLV-1 and foci of TSP/HAM, ${ }^{1}$ our results surprise because of the very high rate of symptomatic infected subjects. In fact, most of those HTLV-1 infected (75\%) patients had at least two or more associated symptoms. Despite the fact that among these HTLV-1 carriers, $40.4 \%$ harboring tax sequences had seronegative profile, a significant association was found between seronegative condition and absence of symptoms $(P<0.01)$. In this sense, it would be interesting to analyze the correlation between the outcome of neurological diseases and absence of specific antibodies against HTLV-1. In this study, a significant association was observed between sensory symptoms/autonomic nervous system dysfunction and seronegative condition, but not with motor/peripheral symptoms. Similar to findings from other authors, ${ }^{23}$ motor signs and symptoms were highly prevalent among symptomatic subjects in this study, but sensory signs were more prevalent: $78.6 \%(70 / 89)$ versus 52.8\% (47/89). However, analyzing each serological status group separately, motor symptoms were the most prevalent symptoms among seropositive subjects, whereas sensory symptoms predominated among seronegative ones (Table 1). In coincidence with data from a prospective cohort of blood donors in the United States, ${ }^{24}$ several motor abnormalities were detected in some subjects without overt HAM (data not shown).

Given a broad analysis of a 1,004-bp tax gene, seronegative HTLV-1 carriers showed high homology with seropositive subjects from the same endemic zone of Argentina. Moreover, this tax sequence from seronegative subjects was 99.3-99.6\% homologous with ATK-1 clone. Thereby, these findings demonstrate and confirm that the amplified sequence corresponds to HTLV-1. An interesting contribution of this study is that the analysis was performed on a greater length fragment of tax gene compared with previous studies of seronegative tax-only subjects, in which just small-length sequences of tax were amplified. ${ }^{4,5,19}$

We were unable to amplify other viral genes (env and LTR sequences) in seronegative subjects. According to other authors, tax-only and other seronegative profiles in HTLV-1 carriers could be explained through the presence of defective provirus in the PBMCs. ${ }^{3-5,19,21}$ Also, it has been suggested that the presence of a defective HTLV-1 provirus without LTR sequences in TSP/HAM patients can be due to a vigorous immune response in early infection, which successfully eradicates infected cells and leaves those with defective sequences. $^{3}$

Despite samples of these seronegative subjects having been retested and getting the same molecular biology results, ideally the samples should indeed also be processed in a second laboratory. The latter is a limitation of the study.

Although we describe a very low degree of variation on a great length of tax sequence from eight seronegative subjects, two common nucleotide changes at position 8002 and 8295 were exclusively found in most seronegative tax sequences (5/ 8 ) and were absent in 26 randomly selected sequences from seropositive subjects. Although these mutations did not produce any change on amino acids in Tax protein, it is interesting to highlight that four of five seronegative subjects carrying the mutations were symptomatic adults. The remaining subject was a 10-year-old only child, who was asymptomatic. The other three seronegative patients without mutation were asymptomatic adults. These findings suggest that search for these mutations in other cohorts of seronegative HTLV-1 carriers along with follow-up studies would be necessary to clarify their role in virus pathogenesis.

One of the main contributions of our study is the description, for the first time, of proviral load in seronegative HTLV-1 carriers. The proviral load in blood was quantifiable in all seronegative and tax-positive subjects evaluated. Although the median proviral load of seropositive subjects was significantly higher than the values of seronegative ones (Table 1), the rates were considerably higher, and in some cases, exceeded values of seropositive patients. It has been proposed that the reason for seronegativity in TSP/HAM patients could be an infection with extremely low amount of HTLV-1. ${ }^{5}$ In this sense, our results show that this statement is not adequate for all HTLV-1 carriers with seronegative profile. Follow-up of this cohort would be interesting to elucidate the association between the load of tax gene and outcome of disease.

Although no antibodies against structural HTLV-1 antigens were detected in seronegative tax-positive subjects, almost $40 \%$ of them had antibodies against viral Tax protein. The antibody against Tax is another evidence of infection in these HTLV-1 carriers, demonstrating previous viral activity. Moreover, no correlation between proviral load and IgG anti-Tax reactivity was observed when comparing seropositive and seronegative HTLV-1 carriers (Figure 3). This is in agreement with previous reports of other cohorts, ${ }^{25}$ corroborating that they are independent biomarkers of HTLV-1 infection.

It has been suggested that anti-Tax antibodies are involved in TSP/HAM pathogenesis. ${ }^{26}$ We found IgG anti-Tax HTLV-1 antibodies in seropositive and seronegative HTLV-1 carriers; 
however, titers were significantly higher in seropositive subjects than in seronegative ones $(P<0.0001)$ (Figure 2). Thus, the pathogenic role of these antibodies and their titers in infected subjects, especially in seronegative HTLV-1 carriers, requires further study. Recently, researchers from Brazil reported a significant difference in HTLV-1 anti-Tax antibody titers between asymptomatic and HAM/TSP patients, suggesting that the presence of anti-Tax antibodies contributes to the aggravation of HTLV-1 infection and is a marker of disease evolution. ${ }^{25}$

It is well established that transmission of HTLV-1 infection may occur by transfusion of cellular blood products. ${ }^{1}$ Because virus carriers usually have antibodies against viral structural antigens, testing for such antibodies with the commercially available CE-marked or FDA-approved HTLV-1/2 screening assays is carried out in Argentina since 2004 (National Blood Law 22.990/83). However, the finding of seronegative HTLV-1 carriers that cannot be detected by these screening assays constitutes a serious challenge for diagnosis and transfusion safety.

One of the first reports of only anti-Tax antibodies in the absence of antibodies against structural antigens of HTLV is a study of intravenous drug users in $1989 .{ }^{27}$ Later, other studies demonstrated similar evidences in blood donors ${ }^{11,19}$ and patients with MF. ${ }^{28}$ We agree with these authors on the need to include other HTLV-related antigens in addition to structural ones in serological tests to identify HTLV-infected individuals, because the findings underscore the fact that individuals considered seronegative based on current tests can be infected with HTLV. Thereby, it is important to provide a new generation of highly sensitive serological assays for HTLV-1 screening and to review current diagnosis algorithms to include molecular assays complementing antibody detection, especially for countries with endemic areas, such as Argentina.

Received August 30, 2019. Accepted for publication January 5, 2020. Published online February 10, 2020.

Acknowledgment: The American Society of Tropical Medicine and Hygiene (ASTMH) assisted with publication expenses.

Disclaimer: The funders had no role in the study design, collection, analysis, and interpretation of the data, or paper writing. The first and last authors had full access to the database and take final responsibility for submitting this manuscript.

Authors' addresses: Sandra Gallego, María C. Frutos, Sebastián Blanco, Gonzalo Castro, Marcos Balangero, and Silvia Nates, Instituto de Virología "Dr. J. M. Vanella," Facultad de Ciencias Médicas, Universidad Nacional de Córdoba, Córdoba, Argentina, E-mails: svgallego@ gmail.com, mariaceliafrutos@gmail.com, seba_36@hotmail.com, gonmcastro@gmail.com, marcosbalangero@yahoo.com.ar, and snates@ fcm.unc.edu.ar. David Elías Panigo and Arnaldo Mangeaud, Departamento de Matemática, Facultad de Ciencias Exactas, Físicas y Naturales, Universidad Nacional de Córdoba, Córdoba, Argentina, E-mails: david.elias949@gmail.com and amangeaud@yahoo.com.ar. Carlos Remondegui, Servicio de Infectología y Enfermedades Tropicales, Hospital San Roque, San Salvador de Jujuy, Argentina, E-mail: remondegui@gmail.com. Anderson Santos Rocha, Gabriela Melo Franco, Marina Lobato Martins, and Edel Figueiredo BarbosaStancioli, Laboratorio de Virología Básica e Aplicada, Departamento de Microbiología, Instituto de Ciencias Biológicas, Universidade Federal de Minas Gerais-UFMG, Belo Horizonte, Brazil, E-mails: anderson.asdr@gmail.com, gabymelofranco@yahoo.com.br, marina. martins@hemominas.mg.gov.br, and edelfb@ufmg.br.

\section{REFERENCES}

1. Gessain A, Cassar O, 2012. Epidemiological aspects and world distribution of HTLV-1 infection. Front Microbio/ 3: 388.
2. Frutos MC et al., 2017. Silent dissemination of HTLV-1 in an endemic area of Argentina. Epidemiological and molecular evidence of intrafamilial transmission. PLoS One 12: e0174920.

3. Daenke S, Parker CE, Niewiesk S, Newsom-Davis J, Nightingale $\mathrm{S}$, Bangham CR, 1994. Spastic paraparesis in a patient carrying defective human T-cell leukemia virus type I (HTLV-I) provirus sequences but lacking a humoral or cytotoxic T-cell response to HTLV-I. J Infect Dis 169: 941-943.

4. Ramirez E, Cartier L, Rios M, Fernandez J, 1998. Defective human T-cell lymphotropic virus type I (HTLV-I) provirus in 10 Chilean seronegative patients with tropical spastic paraparesis or HTLV-I-associated myelopathy. J Clin Microbiol 36: 1811-1813.

5. Ramirez E, Fernandez J, Cartier L, Villota C, Rios M, 2003. Defective human T-cell lymphotropic virus type I (HTLV-I) provirus in seronegative tropical spastic paraparesis/HTLV-I-associated myelopathy (TSP/HAM) patients. Virus Res 91: 231-239.

6. Cartier L, Ramirez E, 2005. Presence of HTLV-I Tax protein in cerebrospinal fluid from HAM/TSP patients. Arch Virol 150: 743-753.

7. de Oliveira Mde F, Fatal PL, Primo JR, da Silva JL, Batista Eda S, Farré L, Bittencourt AL, 2012. Infective dermatitis associated with human T-cell lymphotropic virus type 1: evaluation of 42 cases observed in Bahia, Brazil. Clin Infect Dis 54: 1714-1719.

8. Zucker-Franklin D, 2001. The role of human T cell lymphotropic virus type I tax in the development of cutaneous T cell lymphoma. Ann N Y Acad Sci 941: 86-96.

9. Zucker-Franklin D, Pancake BA, Brown WH, 2002. Prevalence of HTLV-I Tax in a subset of patients with rheumatoid arthritis. Clin Exp Rheumatol 20: 161-169.

10. Morozov VA, Syrtsev AV, Ellerbrok H, Nikolaeva EV, Bavykin AS, Pauli G, 2005. Mycosis fungoides in European Russia: no antibodies to human T cell leukemia virus type I structural proteins, but virus-like sequences in blood and saliva. Intervirology 48: 362-371.

11. Zucker-Franklin D, Pancake BA, Marmor M, Legler PM, 1997. Reexamination of human T cell lymphotropic virus (HTLV-I/II) prevalence. Proc Natl Acad Sci USA 94: 6403-6407.

12. Gallego S, Recalde A, Gastaldello R, Isa M, Nates S, Medeot S, 1997. Kinetics study of human retrovirus antigens expression in T lymphocytic cell lines by indirect immunofluorescence assay. Viral Immunol 10: 149-157.

13. Vandamme AM et al., 1997. Use of a generic polymerase chain reaction assay detecting human T-lymphotropic virus (HTLV) types I, II and divergent simian strains in the evaluation of individuals with indeterminate HTLV serology. J Med Virol 52: $1-7$.

14. Furukawa $Y$, Yamashita M, Usuku K, Izumo S, Nakagawa M, Osame M, 2000. Phylogenetic subgroups of human T cell lymphotropic virus (HTLV) type I in the tax gene and their association with different risks for HTLV-I-associated myelopathy/ tropical spastic paraparesis. J Infect Dis 182: 1343-1349.

15. Liu HF, Goubau P, Van Brussel M, Van Laethem K, Chen YC, Desmyter J, Vandamme AM, 1996. The three human T-lymphotropic virus type I subtypes arose from three geographically distinct simian reservoirs. J Gen Virol 77: 359-368.

16. Castro GM, Balangero MC, Maturano E, Mangeaud A, Gallego SV, 2013. Development and validation of a real-time PCR assay for a novel HTLV-1 tax sequence detection and proviral load quantitation. $J$ Virol Methods 189: 383-387.

17. De Souza JG, Fonseca FG, Martins-Filho OA, Teixeira-Carvalho A, Martins CP, Carvalho LD, Coelho-Dos-Reis JG, BarbosaStancioli EF; GIPH, 2010. Diagnostic tool based on an HTLV-1 Tax expression system in eukaryotic cells using a poxvirus vector. J Virol Methods 166: 65-71.

18. Mangeaud A, Elías Panigo DH, 2018. R-Medic. Un programa de análisis estadísticos sencillo e intuitivo. Revista Methodo 3: 18-22.

19. Zucker-Franklin D, Pancake BA, 1998. Human T-cell lymphotropic virus type 1 tax among American blood donors. Clin Diagn Lab Immunol 5: 831-835.

20. Barrientos A, Lopez M, Sotomayor C, Pilleux L, Calderón S, Navarrete M, Otth C, 2011. Prevalence of human T-cell lymphotropic virus type 1 and 2 among patients with malignant hematological diseases in south Chile. J Med Virol 83: 745-748. 
21. Kojima Ket al., 1999. Defective human T-lymphotrophic virus type I provirus in T-cell prolymphocytic leukaemia. $\mathrm{Br} J$ Haematol 105: 376-381.

22. Miyoshi I, Takemoto S, Taguchi H, Taguchi F, Sawada T, 2002. Adult T-cell leukemia with cyclic neutropenia in a seronegative patient carrying only the tax gene of HTLV-I. Am J Hematol 71: 137-138.

23. Gessain A, Mahieux R, 2012. Tropical spastic paraparesis and HTLV-1 associated myelopathy: clinical, epidemiological, virological and therapeutic aspects. Rev Neurol (Paris) 168: 257-269.

24. Biswas $\mathrm{HH}$ et al., 2009. Neurologic abnormalities in HTLV-I- and HTLV-II-infected individuals without overt myelopathy. Neurology 73: 781-789.

25. De Souza JG, da Fonseca FG, Martins ML, Martins CP, de Carvalho LD, Coelho-dos-Reis JG, Carneiro-Proietti AB,
Martins-Filho OA, Barbosa-Stancioli EF; GIPH, 2011. Anti-Tax antibody levels in asymptomatic carriers, oligosymptomatic carriers, patients with rheumatologic disease or with HAM/TSP do not correlate with HTLV-1 proviral load. J Clin Virol 50: 13-18.

26. Levin MC, Lee SM, Kalume F, Morcos Y, Dohan FC Jr., Hasty KA, Callaway JC, Zunt J, Desiderio D, Stuart JM, 2002. Autoimmunity due to molecular mimicry as a cause of neurological disease. Nat Med 8: 509-513.

27. Ehrlich GD et al., 1989. Detection of anti-HTLV-I tax antibodies in HTLV-I enzyme-linked immunosorbent assay-negative individuals. Blood 74: 1066-1072.

28. Pancake BA, Zucker-Franklin D, Coutavas EE, 1995. The cutaneous $T$ cell lymphoma, mycosis fungoides, is a human $T$ cell lymphotropic virus-associated disease. A study of 50 patients. J Clin Invest 95: 545-554. 